\title{
Impact factors in sustainable economic development
}

\section{Factores de incidencia en el desarrollo económico sostenible}

\author{
ACOSTA-MELLADO, Erika Ivett†*, LANZADURI-AGUILERA, Yara and MURILLO-FÉLIX, \\ Cecilia Aurora
}

Instituto Tecnológico de Sonora

ID $1^{\text {st }}$ Author: Erika Ivett, Acosta-Mellado / ORC ID: 0000-0003-3526-8923, Researcher ID Thomson: X-8807-2019, CVU CONACYT ID: 282641

ID $1^{\text {st }}$ Coauthor: Yara, Lanzaduri-Aguilera / ORC ID: 0000-0002-7784-2762, Researcher ID Thomson: S-6759-2018, CVU CONACYT ID: 625073

ID $2^{\text {nd }}$ Coauthor: Cecilia Aurora, Murillo-Félix / ORC ID: 000-0002-2214-9880, CVU CONACTY ID: 971874

DOI: $10.35429 /$ JAF.2019.19.6.18.25

Received September 20, 2019; Accepted November 29, 2019

\begin{abstract}
This study is carried out with the purpose of determining the correlational-causal relationship between the variables sustainable economic development, equitable social development, efficient and participatory institutional development and technology, for this the following methodology was developed: a quantitative study, with a non-experimental design, of transectional cut. The measurement instrument used was the questionnaire, consisting of three independent and one dependent variables, with 71 questions. Each construct contains a series of items that are related to the variable to be measured. The statistical methods that were considered the most appropriate for the analysis of the data collected were: cronbach's alpha, to measure the reliability of the instrument and; the multiple linear regression method for checking the model. The results obtained show that there is a positive relationship between the variables and, with the ANOVA test it was possible to verify that the three independent variables proposed in the theoretical model are statistically significant, since they have a significance level of 0.000 , therefore it is considered relevant. The contribution of this research lies in granting the input of strategies to the authorities of the surveyed municipality to help improve their economic conditions.
\end{abstract}

Development, Economic, Sustainable

\begin{abstract}
Resumen
Este estudio se realiza con la finalidad de determinar la relación correlacional-causal entre las variables desarrollo económico sostenible, desarrollo social equitativo, desarrollo institucional eficiente y participativo y tecnología, para ello se desarrolló la siguiente metodología: un estudio cuantitativo, con diseño no experimental, de corte transeccional. El instrumento de medición utilizado fue el cuestionario, compuesto por tres variables independientes y una dependiente, con un total de 71 preguntas. Cada dimensión contiene una serie de ítems que están relacionados con la variable que se desea medir. Los métodos estadísticos que se consideraron los más apropiados para el análisis de los datos recolectados fueron: el alfa de cronbach, para medir la confiabilidad del instrumento y; el método de regresión lineal múltiple para la comprobación del modelo. Los resultados obtenidos demuestran que existe una relación positiva entre las variables y, con la prueba ANOVA se pudo comprobar que las tres variables independientes propuestas en el modelo teórico son estadísticamente significativas, ya que tienen un nivel de significancia de 0.000 , por lo tanto se considera pertinente. El aporte de esta investigación radica en otorgarles a las autoridades del municipio encuestado un insumo para el planteamiento de estrategias que coadyuven a mejorar sus condiciones económicas.
\end{abstract}

Desarrollo, Económico, Sostenible

Citation: ACOSTA-MELLADO, Erika Ivett, LANZADURI-AGUILERA, Yara and MURILLO-FÉLIX, Cecilia Aurora. Impact factors in sustainable economic development. Journal of Administration and Finance. 2019, 6-19: 18-25

*Correspondence to Author (email: erika.acosta@itson.edu.mx)

$\dagger$ Researcher contributing first author. 


\section{Introduction}

In the first section the background is shown and the problem that gives rise to this research is analyzed. Subsequently, the general objective is established, and the delimitations and limitations of the study are described. In the second section the theoretical bases of the article are developed. The third describes the methodological design that, for the purposes of this investigation, is considered appropriate. The fourth section describes the way in which the statistical analysis was carried out and the results obtained from it. The sponsor of the project is mentioned in the fifth section; the conclusions of the study are described in the sixth and finally the references used in this article are incorporated.

\section{Background}

During the industrial revolution of the nineteenth century, the world was immersed in the idea of achieving economic growth and there was a great boom in the use of energy resources, creation of factories, etc ; later, the social term was included along with the economic, since the technological and economic advance that was being presented would improve the social life of the world.

But it was in 1930 when specially developed countries, they realized the value and importance in the economic and social growth of natural resources and the environment, both extremely neglected to that date.

Industrial development ends day by day with natural resources, destroys ecosystems, causes the loss of ecological diversity, and reduces the resilience of the planet. Likewise, the depletion of energy resources and raw materials brings the next generation to a total lack of them.

The fact that they have limited natural resources that can be depleted and the desire to grow economically without taking them into account producing serious environmental problems has led countries to consider and discuss more often the problem of achieving social, economic and environmental development as a whole, which they have called sustainable development.

\section{Problem Statement}

The economic system based on unlimited exploitation of resources, maximum production, consumption, and profit as the sole criterion of good economic progress is unsustainable. A limited planet cannot provide the resources that this exploitation would require indefinitely. For this reason, the idea has been imposed that a real development must be sought, which allows the improvement of living conditions, but compatible with a rational exploitation of the planet that takes care of the environment.

America is in a productive transformation that increases the intervention of society, seeking to exploit natural resources to improve living standards and conditions. However, this same society knows that the quality of life of the population cannot be improved at the cost of their standard of living, that is why natural capital is essential to achieve productive transformation with equity.

Development processes affect the quality of the environment, for example, water and air pollution decrease the ability of ecosystems to deliver goods and services to the population.

This leads to the integration of different dimensions: the ecological, economic and social, that is, natural resources must be taken care of, rationally exploiting them without neglecting the economic base; In addition to integrating the concept of intragenerational equity, all this in the field of sustainable development.

The term sustainable development means "satisfying the current needs of society without affecting the vital possibilities of the next generations", García-Colín Sherer (1996). In other words, it is necessary that by obtaining resources from nature to meet present needs, the potential for future development is not affected. This necessarily implies extracting natural resources at rates that do not prevent the regeneration of ecosystems.

The basis of sustainable development is: the structure of incentives, legislation and the management and organization of productive activities. It depends on the systems for assigning property and tenure rights, economic and social incentives, the management of the economy and resources, the role of the State, companies and communities of different types and individuals.

ACOSTA-MELLADO, Erika Ivett, LANZADURI-AGUILERA, Yara and MURILLO-FÉLIX, Cecilia Aurora. Impact factors in sustainable economic development. Journal of Administration and Finance. 2019 
In Mexico, it is based on a disadvantageous situation, due to long periods of neglect of the environmental education and training of its resources, the promotion of science, technological innovation, business strengthening and the reduction of social and income inequality.

These lags cannot be remedied in the short term, but it will never be too late to start programs that are well oriented to the challenge of undertaking processes that lead to sustainable development in all orders and place the environment above any other material consideration.

In 45 years, a third of the population of the State of Sonora, ceased to be rural and became urban. In 1950, $45.9 \%$ of the total population was rural, by 2005 it represented $14.2 \%$ (340,800 inhabitants), as a result of emigration as a result of the lack of development opportunities, INEGI (2008).

Difficult access to education, land, productive resources, deterioration of natural resources and marginalization are indicators that stand out in the current situation of rural communities, as well as the need for better basic services.

Taking sustainable development as a frame of reference, the analysis carried out in the previous paragraphs leads to the following research question: Is there a correlational-causal relationship between the dependent variable sustainable economic development and the independent variables: equitable social development, efficient institutional development and participatory and, technology?

\section{Justification}

Rural communities are rich in ecological and cultural diversity. The size and complexity of these communities makes it difficult to generalize their problems or their assets, although there are some common ties. For much of its existence, rural communities have relied on the wealth of natural resources in the environment. But in the twentieth century major technological, political and economic changes have brought a profound transformation to agriculture and renewable resource industries and to the rural communities dependent on them.
Some rural communities face a loss of inhabitants, while others, particularly those of high scenic or recreational value, must face the problem of rapid population growth that brings new demands to the ecosystem and traditional ways of life.

For the rural environment, the rapid pace of change brings not only challenges but also opportunities. Somehow, sustainable development aims to handle change that is inevitable, and to do so in a way that is economically valid, environmentally responsible and socially fair. The most successful communities struggle to build on their local strengths and abilities while adopting and adapting new ideas and technologies to the local context.

The application of the principles of sustainable development, within Mexican communities is extremely necessary. Making the inhabitants progress economically and socially using the resources at hand without seriously altering the environment and advancing socially is a colossal task, which should not be long.

The present investigation is considered pertinent, since when carrying out its objective it will be possible to verify the existing relationship between the variables indicated in the research question, derived from the application of the principles of sustainable development. On the other hand, with the development of this document, an antecedent will be generated that, possibly, serves as a reference for other researchers who wish to verify the existence of such a relationship in a rural community in Mexico.

\section{Objective}

To determine the correlational-causal relationship between the dependent variable sustainable economic development and the independent variables: equitable social development, efficient and participatory institutional development, and technology, through the use of a statistical model. 


\section{Hypothesis}

H1. There is a correlational-causal relationship between the dependent variable sustainable economic development and the independent variables: equitable social development, efficient and participatory institutional development and, technology.

H2. Equitable social development, efficient and participatory institutional development and, technology positively impact sustainable economic development.

\section{Delimitations}

\section{Space}

This investigation was carried out in one of the thirty-one states that, together with Mexico City, form the United Mexican States, in Sonora, located in the northwestern region of the country, bordering north with Arizona (United States), east with Chihuahua, to the south with Sinaloa and to the west with the Sea of Cortez or Gulf of California (Pacific Ocean).

Specifically, in the community of Etchojoa having an area of $1,220 \mathrm{~km}^{2}$. The municipality is located in the south of the State and borders to the north and east with Navojoa, to the south with Huatabampo, to the northwest with Cajeme and to the west with the Sea of Cortez.

The following towns belong to this municipality: Vasconia, Bacame Nuevo, Basconcobe, Buaysiacobe, Bacobampo, Campanichaca, Caurarajaqui (La Soto), Chucarit, Sahuaral, Las Mil Hectareas (Las Miles), Las Playitas, Mochipaco, Mocorúa, San Pedro, Villa Three Crosses, among many others.

Etchojoa means "Cactus House" in Cahita (Etcho: Stenocereus thurberi). Etchojoa is one of the seven villages that make up the May ethnic group, according to the encyclopedia of the Municipalities of Mexico, consulted in August 2019.

\section{Demographic delimitation}

Inhabitants of the municipal seat of Etchojoa, within the age range of 25-45 years considered in productive age.

\section{Limitations}

The investigation considers three independent variables and one dependent, within the framework of sustainable development, the environmental development variable being outside the scope of this study, since during the work with the Municipality of Etchojoa, it was analyzed independently for the purpose of the implementation of strategic environmental development programs.

\section{Theoretical framework}

The modern development perspective not only seeks to raise the levels of well-being of today's human societies but is concerned about the possibility of inheriting a planet with plausible levels of economic, social and environmental health from future generations. Hence, the analysis of human behavior, needs to transform attitudes and redefine the trends that point to massive damage or environmental destruction; the increasingly demanding population, which will affect more food, housing, consumer goods and entertainment focused on economic growth by applying a dramatic pressure on natural resources.

On this principle, the concept of sustainable development emerges whose definition establishes that it is a development that meets the needs of the present without compromising the ability of the future to meet their own.

The conceptual framework of sustainable development presents several approaches depending on the disciplinary approach that addresses it. Thus, for some the important thing is the use of renewable natural resources, in such a way that it does not deplete or degrade and accrue a real reduction of its renewable utility for future generations, keeping constant inventories of natural resources.

Development does not necessarily mean economic growth; the type of economic activity can change without increasing the amount of goods and services. It is said that economic growth is not only compatible with sustainable development, but it is necessary to mitigate poverty, generate resources for development and prevent environmental degradation. The question is the quality of growth and how its benefits are distributed not only the mere expansion.

ACOSTA-MELLADO, Erika Ivett, LANZADURI-AGUILERA, Yara and MURILLO-FÉLIX, Cecilia Aurora. Impact factors in sustainable economic development. Journal of Administration and Finance. 2019 
Frequently, sustainable development is also defined as development that improves health care, education and social welfare. It is currently admitted that human development is decisive for economic development and for the rapid stabilization of the population. Some authors have further extended the definition of sustainable development by including a rapid transformation of the technological base of industrial civilization; for which they point out that it is necessary that the new technology be cleaner, more efficient and save natural resources in order to reduce pollution, help stabilize the climate and adjust population growth and economic activity.

In the Rio Declaration of 1992, a transcendental commitment was assumed: the adoption of the objective of sustainable development, that is, an economic and social development that includes environmental protection and respect for natural resources, that is equitable and ensures generations to come to access to resources and non-polluting technologies to improve the quality of life worldwide. No country has yet undertaken an integrated sustainable development process.

It is not a technical issue, but a social and political one: it requires mobilizing the necessary resources, giving priority to the new objective, combining government efforts with business and those of civil society, creating awareness of the dangerous and even irreversible thresholds that may arise, build a culture of knowledge and communication that contributes to sustainable development.

Treviño (2003), quotes Dr. Paolo Bifani, in his work Environment and Development, which believes that multiple definitions of sustainability generally isolate some elements of the conceptual organic body of which they are an integral part, thus Bifani distinguishes and It describes four approaches: the environmentalist, the intergenerational, the sectorial and the economic. This orientation can be argued from the Brundtland report that reads: "We see the possibility of a new era of economic growth that must be based on policies that sustain and expand the resource base of the environment; and we believe that such growth is absolutely indispensable to alleviate the great poverty that continues to accentuate in much of the developing world. " Extreme economic growth is seen as a condition of sustainable development.
On the other hand, it is said that sustainable development must be combined with economic growth, with the strengthening of competitiveness, with better management of nature and biodiversity, as well as with a decrease, in absolute terms, of hazardous emissions. For the environment this conception is committed to a "smart growth" of the economy, assuming that the general pressure on the environment decreases. It is argued that it is natural for humanity to fight for the continued growth of production and consumption. Economic growth is considered vital for the sustainable development of the world.

Other authors have considered within the approaches, the social, institutional and technological dimension. For Díaz (2003), the social dimension of sustainable development consists in recognizing the right to equitable access to common goods for all human beings, in intra-generational and inter-generational terms, both between genders and between cultures..

The social dimension not only refers to the spatial and age distribution of the population, but also refers, in a special way, to the set of social and economic relations that are established in any society and that are based on the region, the ethics that are established in any society and based on religion, ethics and culture itself. Also, this dimension has as a mandatory reference to the population and pays special attention to their forms of organization and participation in decision making. It also refers to the interactions between civil society and the public sector.

Within the institutional dimension, it can be mentioned that sustainability is one of the most powerful challenges, and this implies not only the elaboration of diagnoses and proposals, but also deep transformations at the national, state, and local level, being the last one that lies with greater interest for a viable development, since by incorporating them and taking them into account for higher decisions, they cease to be only recipients of opportunities and are responsible for undertaking ideals that best suit their situation and start their path to development (Enriquez, 2004).

Acceleration of technological innovation and development is required to reduce the natural resource content of certain economic activities, as well as to improve the quality of production.

ACOSTA-MELLADO, Erika Ivett, LANZADURI-AGUILERA, Yara and MURILLO-FÉLIX, Cecilia Aurora. Impact factors in sustainable economic development. Journal of Administration and Finance. 2019 
The technological dimension implies the search and change towards more efficient technologies in the case of industrialized countries and the development of more efficient and clean technologies in countries of rapid industrialization. In developing countries with agriculture-based economies, it is necessary to develop appropriate and small-scale technologies for increasing agricultural productivity.

\section{Methodology}

This section addresses the main elements of the methodology to be developed.

According to Hernández, Fernández, and Baptista (2010), the type of research is nonexperimental, this is done without deliberately manipulating the independent variables. It is characterized by being correlational - causal, since it attempts to measure the degree of association between two or more variables in a particular context and the way in which they interact with each other; It also aims to establish the correlation of data to test the hypotheses presented here. With a transectional study, since it focuses on analyzing the level or state of one or several variables at a given time.

The choice of the measuring instrument used was the questionnaire, also called a survey, being a mechanism mostly used to collect data, which consists of a group of questions concerning one or more variables, consisting of 3 independent variables and 1 dependent variable, with A total of 71 questions. Each variable was defined according to the methodology proposed by Wong (2005), each dimension contains a series of questions that are related to the variable to be measured.

The measurement levels used for the items that make up the questionnaire are of order of scale. The scaling method is of the Likert type (1932) in Hernández et al (2010), this refers to a set of items presented in the form of an affirmation or judgment, where the subject or respondent is asked to extinguish his reaction by choosing one of the six points of the scale, and each point corresponds to a numerical value. So that in the end, adding all the scores obtained in relation to the statements, the interviewee obtains a total score. The minimum score for the items was one and the maximum six.
The measures were defined as follows:

$\begin{array}{ll}\text { 1. } & \text { Null / nonexistent } \\ \text { 2. } & \text { Very low } \\ \text { 3. } & \text { Low } \\ \text { 4. } & \text { Medium / minimum acceptable } \\ \text { 5. } & \text { High } \\ \text { 6. } & \text { Very high }\end{array}$

The dimensions of the instrument are:

1. Sustainable Economic Development, (DES).

2. Equitable Social Development, (DSE).

3. Efficient and Participatory Institutional Development (DIEyP)

4. Technology, (T).

The population is the total set of analysis units. The populations must be clearly placed around their characteristics of content, place and time. The study population is composed of 20,666 research subjects, data provided by the $H$. City Council of Etchojoa at the beginning of the investigation in May 2019.

To determine the sample size, according to Morales (2012), the type of probabilistic sampling was used and within it the simple random was chosen. Knowing the population size, the necessary sample is smaller and its size is determined by the formula:

$$
n=\frac{N}{1+\frac{e^{2}(N-1)}{Z^{2} p q}}
$$

where:

$\mathrm{n}=$ sample size that you want to know

$\mathrm{N}=$ known population size, e, $\mathrm{z}$ and $\mathrm{pq}$ (or $\sigma 2$ ) as before.

$n=\frac{20,066}{1+\frac{0.3^{2}(20,066-1)}{1.96^{2}(.25)}}$

$n=377$

For the analysis of the data, statistical tests were performed using the IBM SPSS Statistics version 21.0 software. As a first step, the constructs were designed, later the regression model was created and finally the different indicators of the model were analyzed comparing the results obtained, with the parameters suggested for each indicator. 


\section{Results}

This section shows the statistical analysis of the data collected on 377 surveys applied in the research process.

As can be seen in Table 1, the results obtained from the cronbach alpha for the variables do not present values below .600 , for this reason it is inferred that the results manifest internal consistency; that is, they show correlation between the questions of the instrument.

\begin{tabular}{|l|r|}
\hline Dimension & $\begin{array}{c}\text { Cronbach's } \\
\text { alpha }\end{array}$ \\
\hline DES & .902 \\
\hline DSE & .879 \\
\hline DIEyP & .912 \\
\hline T & .831 \\
\hline
\end{tabular}

Table 1 Results of the cronbach alpha calculation Source: Own elaboration with data from the surveys captured in the IBM SPSS Statistics 21 software, (2019)

The correlation coefficient shows the degree of relationship or association between the study variables. The degree of linear relationship can vary from a perfect negative correlation of 1.0 to a perfect positive correlation of +1.0 . The magnitude of the relationship is indicated by the absolute value of the correlation coefficient where, the larger the magnitude of correlation, the stronger the relationship between the variables.

In order to determine the correlation between the variables proposed in the model, Table 2 is presented:

\begin{tabular}{|c|c|c|c|c|c|}
\hline & & DES & DSE & DIEyP & $\mathbf{T}$ \\
\hline \multirow{2}{*}{ DES } & Pearson correlation & 1.00 & .636 & .497 & .507 \\
\hline & Sig. (Bilateral) & & .000 & .000 & .000 \\
\hline \multirow{2}{*}{ DSE } & Pearson correlation & .636 & 1.00 & .556 & .516 \\
\hline & Sig. (Bilateral) & .000 & & .000 & .000 \\
\hline \multirow{2}{*}{ DIEyP } & Pearson correlation & .497 & .556 & 1.00 & .477 \\
\hline & Sig. (Bilateral) & .000 & .000 & & .000 \\
\hline \multirow{2}{*}{$\mathrm{T}$} & Pearson correlation & .507 & .516 & .477 & 1.00 \\
\hline & Sig. (Bilateral) & .000 & .000 & .000 & \\
\hline
\end{tabular}

Table 2 Correlations

Note: * The correlation is significant at the 0.05 level (bilateral)

Source Own elaboration with data from the surveys captured in the IBM SPSS Statistics 21 software, (2019)

In Table 3 it can be interpreted that, the corrected R2 of the model indicates that it has a predictive capacity of .459 , in this sense Hair (2006) refers that the predictive power of the model is moderate.
The Durbin-Watson test for serially correlated residues can also be observed. This statistic ranges between 0 and 4 and takes the value 2 when the residuals are completely independent. Values greater than 2 indicate positive autocorrelation and those less than 2 negative autocorrelations. It is usually assumed that the residuals are independent if the $\mathrm{D}-\mathrm{W}$ statistic is between 1.5 and 2.5. The value obtained for this test was 1,485 .

In this same Table 3, it is shown that the ANOVA of the resulting model is statistically significant based on the value obtained in the Sig column, where the result is less than 0.05 , the value of $F$ greater than 2.4. The null hypothesis that the variability observed in the response variable is explained by chance is rejected and it is admitted that there is some kind of association between the dependent and independent variables. Therefore the model is relevant.

In order to determine if there is collinearity, two procedures were used: 1.) The empirical rule, cited by Kleinbaum, Kupper, and Muller (1988), which consists in considering that there are collinearity problems if any IVF is greater than 10. In Table 3, it can be seen that the value obtained is less than 10. 2). For Belsley (1991), condition indices between 5 and 10 are associated with a weak collinearity, while condition indices between 30 and 100 indicate a moderate to strong collinearity. As can be seen in the results of the "Condition Index" in the model, it is less than 30 , so it can be said that there is no multicollinearity problem.

\begin{tabular}{|l|l|}
\hline \multicolumn{1}{|c|}{ Parameters } & \multicolumn{1}{c|}{ Model } \\
\hline Variables selected in the model & $\begin{array}{l}\text { Predictors: } \\
\text { X1. DSE, X2. DIEyP, X3. T }\end{array}$ \\
\hline Dependent variable & DES \\
\hline R squared corrected & .459 \\
\hline Durbin Watson & 1.485 \\
\hline ANOVA & Sig. .000 \\
\hline F & 107.168 \\
\hline FIV & 1.559 \\
\hline Condition index & 19.782 \\
\hline
\end{tabular}

Table 3 Statistical results

Source. Own elaboration with data from the surveys captured in the IBM SPSS Statistics 21 software, (2019)

\section{Acknowledgments}

This project was funded by the Sonora Institute of Technology, through the Program for the Promotion and Support of Research Projects (PROFAPI). 


\section{Conclusions}

For the verification of the research hypotheses, the significance of $\beta$ less than .005 and the signs obtained in the coefficients typified $\beta$ were used as a reference.

The hypotheses are confirmed based on the results obtained, shown in Table 4 , according to the significance of the betas $(\beta)$ :

H1. There is a correlational-causal relationship between the dependent variable sustainable economic development and the independent variables: equitable social development, efficient and participatory institutional development and, technology.

H2. Equitable social development, efficient and participatory institutional development, and technology positively impact sustainable economic development.

It can also be observed in Table 4, according to the signs of the Coefficients typified $\beta$, that all the causal relationships of the model are positive, that is, greater equitable social development presents greater sustainable economic development; to greater efficient and participatory institutional development greater sustainable economic development; to greater technology greater sustainable economic development.

\begin{tabular}{|c|c|c|}
\hline Variables & $\begin{array}{c}\text { Significance of } \\
\text { Beta }(\boldsymbol{\beta})\end{array}$ & $\begin{array}{c}\text { Typified } \\
\text { Coefficients } \beta\end{array}$ \\
\hline $\begin{array}{lll}\text { X1 Equitable Social } & \text { Solopment } \\
\text { Developm }\end{array}$ & .000 & $.446(+)$ \\
\hline $\begin{array}{l}\text { X2 Efficient and } \\
\text { Participatory } \\
\text { Institutional } \\
\text { Development }\end{array}$ & .000 & $.204(+)$ \\
\hline X3 Technology & .001 & $.152(+)$ \\
\hline
\end{tabular}

Table 4 Hypothesis check

Source. Own elaboration with data from the surveys captured in the IBM SPSS Statistics 21 software, (2019)

According to the previous results, the variable that contributes least to the model is that of Efficient and Participatory Institutional Development.

\section{References}

Belsley, D. A. (1991). Conditioning diagnostics. John Wiley \& Sons, Inc.
De México, E. D. L. M. (2005). Enciclopedia de los Municipios de México. Instituto Nacional para el Federalismo y Desarrollo Municipal. local. gob. $\mathrm{mx} /$ work/temples/enciclo/mexico/municipios.

Díaz-Bautista, A., Aviles, J. A., \& Chimal, M. A. R. (2003). Desarrollo económico de la frontera norte de México. Observatorio de la economía latinoamericana, 29-36.

Enríquez Villacorta, A. (2004). Gobernabilidad democrática: una agenda para avanzar al desarrollo en América Latina. Alternativas para el Desarrollo, (87), 1-14.

García-Colín Scherer, L., \& Ephussi, B. (1996). Energía ambiente y desarrollo sustentable:(el caso de México).

Hair, Joseph F., William C. Black, Barry J. Babin, \& Rolph E. Anderson (2006), Multivariate Data Analysis, Englewood Cliffs, NJ: Prentice Hall.

Hernández Sampieri, R., \& Collado, C. F. C. y Baptista Lucio, P. (2010). Metodología de la Investigación. 5ta Edición McGraw-Hill.

Instituto Nacional de Estadística, Geografía e Informática, Censo General de Población y Vivienda 2008. México 2008.

Kleinbaum, D. G., Kupper, L. L., y Muller, K. E. (1988). Applied Regression Analysis and Other Multivariate Methods: Student's Partial Solutions Manual. PWS-Kent.

Likert, R. (1932). A technique for the measurement of attitudes. Archives of psychology.

Treviño, A. R. (2003). El Desarrollo Sustentable: Interpretación y Análisis. Revista del Centro de Investigación de la Universidad la Salle, 6(21), 55-55.

Vallejo, P. M. (2012). Tamaño necesario de la muestra: ¿Cuántos sujetos necesitamos? Estadística aplicada, 24(1), 22-39.

Wong, P. (2005). Propuesta metodológica para el análisis estratégico participativo de desarrollo local-regional. México: Centro de Investigación en Alimentación y Desarrollo, AC (CIAD, AC). 